\title{
4
}

\section{A Prophet in Your Own Land? Using Faculty and Student Focus Groups to Address Issues of Race, Ethnicity, and Gender in the Classroom}

\author{
James Francisco Bonilla and Patricia R. Palmerton \\ Hamline University, St. Paul, Minnesota
}

In this study, six focus groups of faculty and students addressed issues of how race, ethnicity, and gender affected their classroom experiences. Consistent themes emerged across all groups, including feeling unsafe and vulnerable, concerns about equity, power, and role modeling. As importantly, the research process itself became a vehicle for groweth and change in the community at large, both inside and outside the classroom. Six recommendations are offered for those woho seek innovative approaches to addressing race and gender in the classroom.

\section{INTRODUCTION}

ne of the most difficult aspects of faculty and organizational development work is gaining the full commitment of all to the development effort. One of the larger obstacles for faculty developers addressing sensitive issues such as race, ethnicity, and gender is the perception that peers cannot be prophets in their own land. Because of embeddedness in the institution, colleagues are often skeptical of an insider's ability to be neutral or well informed enough to provide new or different insights. This can be especially true for people of color and for women. Often termed "buy-in," the success of a development effort depends upon the willingness of members of the organization to accept the legitimacy of 
the findings, to engage in discussion and problem solving, and then be willing to do the work necessary for growth.

When we began our series of focus groups in the spring of 1997, our purpose was to hear from faculty and students what would help them in addressing the enlivening yet often contentious issues of race, ethnicity, and gender in the Hamline classroom. Our goal at the outset was quite simple: We wanted to know if race and gender were indeed real issues in the classroom for faculty and students. We hoped to discover insights that would help us plan faculty development. What we discovered, however, was that the research process itself resulted in significant growth: for our respondents, for members of the campus community, and for us. In this essay, we will describe the process we used in order to show how attempts to gain insight into the problems faced became a vehicle for change in the community at large. Serendipitously, we became in-house prophets, by legitimizing the voices of those who needed to be heard.

In this essay, we will describe the process used to gain insight into our own institution and its members, and we will touch upon the illuminating, occasionally painful, but always rich texture of experiences revealed through the course of our conversations. With few exceptions, we found that a clear majority of our participants believe race and gender are significant issues both outside and inside the classroom. As the sessions progressed, we asked participants to detail for us how race and gender manifested in their classroom and finally, what would be helpful, from a faculty development perspective, in addressing the issues described.

\section{Methods}

As a qualitative method for data collection, focus groups bring together several participants to discuss topics of mutual interest to them and the researchers (Morgan \& Spanish, 1984). Focus groups have become increasingly popular as a method of applied research as well as for gathering in-depth information about the experiences, ideas, and expectations of specific populations (Kreps, 1995). To quote Kreps, "In the final analysis, although focus groups are not necessarily the best method to use in every applied research context, they are a powerful group facilitation technique that can be used to stimulate group discussion" (p. 199). It was very much our intention that a report to the Hamline community would stimulate discussion about good teaching and the role diversity plays in the classroom. What we did not anticipate was that the focus groups themselves would begin that process. 
Our rationale for choosing the focus group approach is rooted in the qualitative literature and the idea that knowledge based on discovery, insight, and understanding from the perspective of those being studied offers great promise (Krieger, 1985; Lincoln \& Guba, 1985; Merriam, 1988; Orbe, 1998). In particular, understanding the experiences of Hamline faculty and students offered us the greatest promise for contributing to our collective knowledge base as faculty developers, and more importantly, to the understanding of the needs of faculty and students in the classroom. Hence, the overarching purpose of this study was to use an inductive process to discover the resources needed by faculty to help them provide the best educational experiences for all students. One of the disadvantages of focus groups is concern over the generalizability of the data gathered given the small sample size. To overcome this limitation, we intentionally designed a process that was as participative as possible.

The project used three faculty and three student focus groups to address issues of race, ethnicity, and gender in the college classroom. The groups lasted approximately one and one-half hours each. Each group was cofacilitated by both researchers, who were Hamline faculty members: one Caucasian female and one Latino male. In this way we could also serve, in part, as peer debriefers (Rossman \& Marshal, 1989). All group sessions were audiotaped and transcribed for later analysis. As researchers, we came to these data with a variety of lenses, male and female, Caucasian and Latino, and as communications studies, education, and organizational behavior scholars. The following summary represents several hundred hours of data gathering and analysis.

Our sample consisted of members of the undergraduate Hamline community. Hamline University is an urban, Methodist-affiliated university with an undergraduate College of Liberal Arts, a law school, and graduate programs in public administration, education, and liberal studies. We focused our attention on the undergraduate College of Liberal Arts. In the College of Liberal Arts, Hamline has approximately 1600 full-time undergraduate students, $65 \%$ female. The students of color population is currently $11 \%$. Many ethnicities are represented, primarily African-American, Hmong, Vietnamese, Cambodian, Native American/American Indian, Hispanic, and Middle Eastern. Our full-time faculty of color population in the College of Liberal Arts stands at 6\%, and $45 \%$ of full-time faculty members are female.

Our sample was self-selecting to the extent that participants answered our letter of invitation. We were fortunate to have CLA faculty volunteer from 13 departments in all five divisions. Our pool of focus 
group participants intentionally constituted a diverse racial and gender representation (16 Caucasian faculty and six faculty of color, 10 males and 12 females). Our student groups were composed of 12 seniors and juniors invited from leadership positions on campus and represented four divisions of the college (fine arts, humanities, social science, and natural science). They included five Caucasian students and seven students of color, four males and eight females. To facilitate the most candid discussions possible, we organized students into separate focus groups, one Caucasian and two groups of color. We did not segregate faculty groups by color.

Our focus group interviews followed a consistent format. All participants received the questions prior to arriving for the interview session (see Figure 4.1). Faculty and students were asked the same questions. We were particularly interested in stories that individuals could tell to illustrate their experiences, and we encouraged participants to expand upon their initial remarks with examples and stories that would help us understand what they meant. There were at least two reasons for the focus on stories. One, narrative accounts include nuances and context that more linear explanations often fail to include. Second, storytelling has been shown to provide means by which other participants can connect their experiences. The stories begun by one person often encourage embellishment by others who add their own stories. A chaining phenomenon can occur, which may signal the existence of a larger interpretive framework functioning across a social grouping (Bormann, 1972; Bormann, Cragan, \& Shields 1994; Bormann, Cragan, and Shields, 1996; Cragan \& Shields, 1981).

Our analysis occurred in several stages. All interviews were transcribed and subjected to analysis by each of the researchers individually. We then met and discussed our analyses. In all cases, we discussed how we had arrived at our interpretations, finding at times that even when we agreed we had different reasons and different perspectives informing our conclusions. These peer analysis sessions were crucial to our design. Before beginning, we made an explicit decision to rely upon our multiple identities-a Caucasian, female Minnesota/South Dakota, Protestant; and a Latino, male New York, Catholic-instead of attempting to somehow overcome them (Merriam, 1988). We did not believe it was possible to overcome them. In fact, we did not believe it would be a positive thing to do so, even if we could. Rather, we attempted to use our lenses as resources, by working to be aware explicitly of the ways in which we were linking with our participants in order to understand them and their 
FIGURE 4.1

Memo to Focus Group Participants

\section{MEMO}

To: $\quad$ Focus Group Participants

From: James Francisco Bonilla, Visiting Sanders Chair in Education Patricia Palmerton, Director of Oral Communication

Date: March 6, 1997

Thank you again for your willingness to participate in the upcoming focus group session. Please read the following information carefully. If you have any questions, please feel free to call either Professor Bonilla or Professor Palmerton.

\section{Statement of Confidentiality and Permission}

As part of the assessment efforts to support both the oral communication program and cultural diversity at Hamline, we are conducting this study looking at race, ethnicity, and gender as they relate to the experience of faculty and students in the classroom. These discussions will be audiotaped for transcription purposes in order to facilitate analysis of the data. All discussion will be confidential, and any names mentioned in the course of discussion will be deleted from the transcripts. Audiotapes will be destroyed at the end of this research.

By your participation we assume your permission to summarize in a report (in a confidential manner) the points and concerns raised in this discussion.

\section{Focus Group Agenda}

I. Introductions and Overview

II. Goals and Ground Rules

III. Questions

A. Some people say race, ethnicity, and gender don't affect what happens in the classroom. Some people say they necessarily affect what happens in the classroom. If you had to take a stand on this, what stand would you take?

B. What kinds of things have happened to you, or to others, that seem related to race, ethnicity or gender?

C. What are the implications of this discussion at the university level? For example, how do you see these experiences related to the way that cultural breadth is working at Hamline?

IV. Closure 
perspectives better. In essence, we attempted to use conscious partiality as a resource rather than as a confounding bias (Mies, 1983).

When we had an initial draft of our findings, we enacted the second stage: member checking. This occurred in two different ways. First, we met with a group of faculty who had been meeting for several months on issues of diversity on campus. Not all members of this group had been participants in our study, but some had. We met with this group first in order to help us see potential problems in the presentation of the data, and, to be frank, to gain moral support. On the basis of feedback provided by this group, we revised the draft. We then sent copies of the revised draft report to all faculty who had participated in the study and invited them to luncheon meetings to discuss the draft, identify concerns they had with the presentation of the data, or concerns about confidentiality. At this point, we were prepared to revise the draft again to address concerns raised, should it become evident we had breached our promises of confidentiality or that we had significantly misinterpreted or missed points that had been expressed.

The third stage consisted of releasing the final draft to the faculty at large, and providing luncheon meetings for any faculty members who wanted to meet to discuss the report. At the fourth stage, we distributed the final draft to the student participants and to student services staff. We specifically did not distribute the draft to this group until faculty had had a chance to review it and discuss it, since the topic of the initial research was classroom interaction. As such, we felt that faculty were potentially vulnerable and deserved to see the report before hearing about it from a student or student services staff member. As a result of distributing the document to student services staff, we were asked to hold another luncheon with those staff members to discuss the implications of the report, so this meeting was added to our process.

What follows are excerpts from the report distributed to faculty, administration, students, and student services staff. Since the focus of this essay is faculty organizational development, we have not included the primary body of the report detailing all the quotations and stories upon which we based our conclusions. In many ways, the findings presented here do not break new ground. Many of these dilemmas have previously been reported elsewhere in the literature on multicultural teaching in the academy (Adams, 1997; Border \& Chism, 1992; Morey \& Kitano, 1997; Schoem, Frankel, Zuniga, \& Lewis, 1995). What does set this effort apart in our estimation was the extent to which our faculty identified with 
these findings. These were not perceived as judgments made by some "external experts" from the "outside." Rather, the process of searching out Hamline faculty and student voices gave the community ownership over the findings, and as we will see later, at developing follow-up recommendations and calls to action and participation.

\section{Selected Findings}

One of the things we found is that Hamline is blessed with a wealth of faculty who care deeply about good teaching and the needs of students, all students. In our interviews, we were struck time and again by the responses from faculty and students that made it clear this is a community that is concerned with doing the right thing. There is a tendency among those interested in social issues like race and gender to catch people doing things wrong. This tendency would do the faculty and students of the Hamline community a serious injustice. In the process of reviewing this report it will be obvious at times that we are not always succeeding to the degree we should or to the degree we want to. Indeed, some of the reports of the painful experiences of students and faculty in our community gave us pause. However, even as we catch ourselves making mistakes, we also must endeavor to catch one another doing things right.

Among the things that we heard faculty members were doing well were stories describing high expectations that encourage students' performance. Often faculty members were perceived as approachable and open, and we heard about heated dialogues or exchanges initiated by faculty on race that resulted in lasting multiracial friendships and understanding. As faculty developers, we emphasize that these positive experiences need to be recognized and emulated: The faculty member that models for others how to deal positively with racist or sexist remarks; the faculty member that assumes capability, despite difficulty with course material. Students mentioned faculty fairness, open-mindedness, and support. "The power of the professor to affect students because of their expectations is phenomenal," said one student in discussing the way in which encouragement from a faculty member helped her overcome previous "horrible" experiences. Students discussed with great appreciation the willingness shown by some faculty members to address issues of race, ethnicity, and gender rather than avoid them.

Nevertheless, both faculty and students identified troubling issues. The next part of this essay highlights some of these concerns. 


\section{Themes Across All Groups}

Five themes were identified which spanned all the focus groups. They were:

1) A pervasive sense of uneasiness. Most faculty and students of color reported feeling uneasy, unsafe, and vulnerable addressing issues of race and gender in the classroom. The pervasive question seemed to be: "Is this a psychologically and emotionally safe place?" Feelings ranged from discomfort to literally feeling psychologically unsafe. Our informants approached the concern about safety differently. Some reported having experienced sanctions that make them feel unsafe. These are most often subtle, for example, "If I bring my ethnicity into something . . . you can hear people breathe out of their noses really hard." Said another student, "[Y]ou can hear them laugh or make snide comments . . . I can feel the tension. It's hard to describe the tension when it does happen, but I can feel it-like needles." Others just feared experiencing sanctions. In general, Caucasian students and Caucasian male faculty were least likely to report having experienced situations that contributed to feelings of dis-ease.

2) Issues of equity in the classroom. Many faculty members were unclear as to how/should/do faculty make special efforts for certain students. Issues raised within this theme included questions about the levels of academic preparedness of students of color, social expectations of Caucasian students and faculty, and whether diverse learning styles in the classroom were being acknowledged.

3) The role of faculty. Faculty were perceived as being powerful and as role models. Yet they were also seen as keepers of the grade, having the ability to punish or protect and to facilitate or deny issues in the classroom. Many of the participants agreed that some faculty members are hesitant to confront issues of race in the classroom.

4) Different needs and at different stages of learning. Faculty and students alike observed that different students bring different understandings of and experiences with issues of race and gender. Many questions were raised about the teaching implications when students at different stages of learning collide. Another concern raised was the teaching implications of having one or two students of color in a class with all Caucasian students when it came to content related issues of race and ethnicity.

5) Institutional commitment. A final theme across all groups was the questioning of institutional commitment. Many sensed a greater 
concern for image than for substance. For example, some groups questioned whether the cultural breadth $(\mathrm{CB})$ requirement was too diffuse, allowing students to avoid issues of race and gender in the United States. Another example was limited CB course offerings that were not sufficiently discipline specific, particularly in math and the sciences. There were concerns about the lack of support for faculty in developing expanded cultural breadth course offerings. This was related to a larger concern questioning the willingness of the institution to address problems related to diversity when they are brought to the attention of institutional decision-makers. Finally, important questions were asked about the adequacy of campus supports that make it likely all students can meet high academic standards.

\section{Selected Themes within Groups}

To further analyze our data we broke down the findings into subthemes by focus group population.

1) What faculty members said were the bardest issues for them. Many faculty felt caught in a cycle of a) not being sure of student preparedness, b) wondering about their own expectations of student performance, and c) wanting to set appropriate expectations. A related dilemma was that when students didn't meet expectations, faculty were unsure how to give feedback without it being be perceived as racist, given differing cultural backgrounds and the expectations carried by the student about the faculty member. There was considerable fear of being seen as a racist or as having a political agenda. All three faculty groups reported confusion about knowing if, or when, or how, to be helpful while simultaneously stressing academic standards.

2) What Caucasian students said are the bardest issues for them. This group unanimously discussed feeling silenced about race, a form of self-censorship. For example, Caucasian students reported being afraid of offending and being thought to be racist. "I'm very careful about what I say because I don't want to be thought of that way [i.e., as racist]." Another student said, "I have not spoken up just because . . . I don't want to be viewed as racist or something . . . so l've just kept my views to myself."

On the one hand, they were aware of their lack of exposure, yet on the other hand they felt expected to be aware of how to interact with students of other races or ethnicities. Like the faculty, they were also dealing with a fear of offending, of being misinterpreted, or seen as racist or 
sexist. Several told stories regarding their struggle to bridge or connect with students of color.

3) What students of color said were the bardest issues for tbem. Nearly all sensed discomfort from Caucasian students and faculty, which was often expressed nonverbally. When confronting subtle responses by Caucasian faculty and students, students of color were at risk of being perceived as "overly sensitive" or "paranoid," fulfilling the confrontational racial/ethnic stereotype, or being misinterpreted. Many students complained about the added expectation that they will educate the campus on issues of race and ethnicity without help from the faculty. Like their Caucasian peers, many students of color felt silenced. Unlike their Caucasian peers, many also reported feeling isolated.

4) Gender matters. The question of needing to protect male students in intense classroom discussions related to gender was widely raised. For example, one faculty member explained "I have to be sensitive to not shut out the males." Some faculty discussed male students as not being ready to confront gender as a social construct. There were also clear differences among faculty regarding levels of comfort with self-disclosure in interactions with students. Some male faculty reported discomfort with relational teaching styles apparently expected by some female students. Female faculty members discussed the difficulty of establishing their authority in the classroom. Women students of color reported difficulty identifying primarily with their gender because they were so strongly identified in terms of race.

5) Identity. Several female faculty and students as well as a number of students of color reported that one strategy for coping with their experiences of discrimination or discomfort was to assimilate themselves with a Caucasian male norm on campus by becoming genderless or invisible racially. While not physically possible, participants described behaving in ways whereby their obvious physical difference was downplayed, ignored, or rendered as irrelevant as possible.

6) Classroom autbority. Many faculty members expressed concerns with establishing their authority and legitimacy in the classroom. These issues manifested differently depending on the gender or racial identity of the faculty member. A number of female faculty and faculty of color reported experiencing classroom challenges to their authority, often unrelated to the topics of race and gender. Several also cited examples of lower evaluation scores for teaching a race or gender related course while a Caucasian/male colleague would be evaluated more 
favorably for the same course and perceived as less biased. A few Caucasian/male faculty members reported challenges to their legitimacy in addressing issues related to race and gender.

\section{Participants' Calls to Action}

In closing each focus group, we asked, "Given the issues raised here today, what would be helpful, from your perspective?" What follows is our summary of participants' responses, organized by population.

\section{1) What faculty said would be belpful to them.}

- help in untangling issues of fairness, favoritism, and equity in the classroom

- help in addressing needs of students with different levels of awareness regarding race and gender

- suggestions for supporting students of color without seeming intrusive

- creation of a more supportive environment rather than a change in academic standards

- refinement of the cultural breadth requirement and expansion of opportunities for additional course creation

\section{2) What Caucasian students said would be belpful to them.}

- greater exposure to racial diversity as a means of learning and developing increased awareness

- in a safe environment, more opportunities to speak and risk making mistakes without fear of being labeled a racist

- Caucasian faculty serving as role models by dealing effectively with racist behaviors in the classroom

- refinement of the cultural breadth requirement and expansion of course options, especially ones that are discipline specific

\section{3) What students of color said would be belpful to them.}

- faculty explicitly admitting their limitations, i.e., "I am still 1 learning and won't get it right," so we all can feel we are in this together

- more space in the classroom to express themselves without fear of intimidating Caucasian students or faculty, a place where a multiplicity of voices can be heard 
- more involvement with the faculty in the classroom and faculty participation in events to educate the broader campus community, to "help shoulder the load"

- refinement of the cultural breadth requirement and expansion of course options

\section{Summary OF Findings}

Across all six groups, it became clear that many of the participants struggled to connect with others. We heard a stream of stories that indicated, to varying degrees, that issues of safety and vulnerability made meaningful engagement with others, both in and out of the classroom, a challenge. Students described a sense of isolation from and lack of connection to diverse communities (including US racial minorities and international students). A majority of students and faculty expressed a discomfort or uneasiness with issues of race when they arose in the classroom.

Throughout all the themes there was a consistent thread: Cultural differences (race, ethnicity, and gender) influence perceptions of behaviors and attributions about the meaning of behavior. In turn, these perceptions and attributions influence choices about how to respond to behavior. Regardless of status as faculty member or as student, all expressed concerns, at times, about ambiguity of meaning and not knowing exactly how to interpret the behaviors they were encountering. It appeared in faculty concerns about how their well-intentioned behaviors would be received, in students' of color frustration about responses to their voices, and in Caucasian students' fears about offending others simply because of their ignorance about what might be offensive. The desire to understand the other better and to be understood by the other was repeated time and again.

We see a snapshot of a campus composed of many diverse voices, perceptions, and behaviors; students and faculty whose preferred ways of communicating differ from the boisterous and animated to the reserved and cautious; many males having been trained in one form of classroom interaction confronting a sometimes new reality of less hierarchical, more relational communication patterns; students who learn through more field-sensitive teaching and those who are more field independent. Sometimes the mix is electric and learning spikes; other times students and faculty felt confused, angry, and/or disappointed.

Hamline reflects a larger American drama of making one community out of the many. To be successful, it seems we will have to resolve the dy- 
namic tensions of those who want more contact and interaction and those who are more comfortable with distance.

In the words of one of our faculty of color describing what it means to come here when one is a student of color and one's experience has not been in a predominantly Caucasian institution:

I describe it as there's this really great house. It's really beautiful, and it's really neat, and it's been built by people who are all 5' 6 " or under. They want you to come because they think it's great that you're a little different from them and they would really like you to come and be in their house, but you're six feet tall. Everything in the house is set up for people $5^{\prime} 6^{\prime \prime}$ and under. You spend all your time bending over, hitting your head on ceilings and things, and you can't quite figure out why you're really uncomfortable, but you notice that your back starts to hurt, and you notice that you don't quite fit, and you notice that everybody else seems really happy but you're feeling kind of miserable. Sometimes they figure out that maybe you're not the right height so they build one room where you can go and stand up. You will have to still operate in the whole rest of the house bent over; it's not comfortable . . . [T] o me as a person of color, that's my experience .. . This is not my cultural world. People relate to me as if I were white. They don't know anything about my culture. So I'm always adapting to them. And having to operate in their world. That's exactly how the students of color talk to me . . . It's more this vague sense of dis-ease.

\section{Recommendations Made to the Campus Community}

A draft of the following recommendations emerged as we wrote our report to the Hamline community. We developed the final recommendations building on the comments, observations, and recommendations of faculty and students made in the "member-check" luncheon meetings. These provided us with a series of possible next steps. We organized these under the relevant themes outlined earlier in this article.

\section{Faculty and Student Exposure}

1) Faculty and students of all colors expressed a need for strategies that can help us confront some of the fears and concerns related to issues 
of race and gender. These include exploring the difference between the intent of our behaviors and the sometimes unintended effect they may have on others. Not unlike undertaking an exercise program after some months of inactivity, addressing these issues inevitably involves some level of discomfort and pain for students. Therefore, it seems equally important that we share processes for ensuring, to the best of our abilities, that students feel safe enough in the classroom to risk exploring these topics with some level of assurance that they will not suffer irreparable harm. However, it must be made clear to them that a safe environment is not necessarily always a comfortable one.

2) Several faculty members asked the question, "How can we be sure our gestures are welcoming gestures?" There was an expressed need for faculty development strategies that enlarge faculty radar for sensing when issues of classroom culture(s) are in conflict (i.e., in communications styles or learning style differences) and when they are not the issues.

3) We heard from students of color, Caucasian students, and a number of faculty that often the classroom environment is not conducive to a multiplicity of voices. For several faculty members, this translates into help in creating an environment in class where it is seen as a safe place to express oneself, particularly on sensitive topics such as race, gender, and ethnicity.

4) The responsibility for tackling discomfort and uneasiness through exposure cannot be relegated entirely to the classroom. Student affairs programming can/must help complement the academic experience as much as possible. To that end, new student orientation can begin to establish as normative the discussion of issues of race, ethnicity, and gender so students are less surprised when they engage these topics in the classroom. These must be continued in hall and campus programming throughout the year.

5) Also under the banner of exposure must come examination of the cultural breadth requirement. A discussion needs to be undertaken on the identified phenomenon of students getting by cultural breadth without the necessity of being exposed to or confronting issues of racial and gender discrimination in the United States. Students are not trying to skirt difficult topics. In several instances, students informed us that it was difficult finding courses that were 
discipline specific to put into their schedules. Efforts can and should be made to expand course options for certain underrepresented majors. This should include institutional support (time and resources) so that faculty can develop course offerings that meet majors' needs. Perhaps a pilot grants program can be developed in-house, or larger grants can be written to outside funders that dovetail and help initiate such curriculum development. One suggestion could be to seek funders that are interested in curriculum innovations that help students prepare for the exigencies of dealing with the dynamics of the changing culture of the workplace or survival skills for students in the next millennium.

6) As part of the new faculty orientation series, at least one session should be devoted exclusively to teaching, learning, and diversity in the classroom. The session should include the challenges of having only one or two students of color in the classroom and dealing with gender dynamics.

\section{Fairness, Favoritism, and Equity}

Many faculty and students expressed varying degrees of ambivalence and confusion over what constitutes fairness, favoritism and equity. Faculty expressed concerns that by reaching out to certain students and not others they might be perceived as not treating all students equally. The two recommendations in this area are as follows:

1) A discussion is needed among faculty addressing what constitutes effective teaching in a classroom with diverse learners. Questions of whether some students learn differently and the implication to the teaching and learning process could shed needed light on these themes. These questions go beyond race and gender and have considerable legal importance when exploring issues of disability in the classroom as well.

2) None of the faculty or students we interviewed was in favor of lowering academic standards. However, a number of faculty members expressed the belief that the key was not in lowering academic standards, but in creating a supportive environment to help students meet those standards. Many faculty and students of color felt the institutional environment had much ground to cover before it could be categorized as supportive. Work on this needs to go forward. 


\section{Addressing Racial and Gender Identity Development}

We heard from faculty and students that they deal with a wide variety of peers who range from the minimally exposed and naive to those in denial or resistant to the angry and confrontational to those who are open and committed to exploring issues of oppression and difference.

1) Classroom dynamics are profoundly influenced by students and faculty at various stages of racial and gender identity development (Adams, Bell, \& Griffin, 1997; Tatum, 1997; Schoem, Frankl, Zuniga, \& Lewis, 1995). Teaching and learning are intertwined with the level of developmental readiness of the learner and teacher. Faculty and staff could benefit from a greater understanding of the stages of racial identity development and their implications to pedagogy. Similar models also pertain to the development of gender identity.

2) One key to helping students of all colors negotiate the transition between stages of racial and gender awareness is the importance of role models and mentors (Adams, Bell, \& Griffin, 1997). Students are heavily influenced by what they see respected faculty and staff doing. We can either engage with these issues (and thus send one message) or avoid issues (thus sending an entirely different message). Discussions need to be undertaken as to how faculty and staff can best influence the campus climate away from uneasiness and toward productive engagement. Students of color were very clear that they sought greater contact with faculty and were especially appreciative of efforts at making a connection. To paraphrase one student, it's okay if faculty admit they may make mistakes ... that way we're all in it together.

\section{Conclusion}

We found that race and gender were indeed real issues in the classroom. We developed insights into what faculty and students felt would be helpful in addressing these concerns. A serendipitous discovery was that the research process itself yielded tangible faculty development benefits; namely, it engendered campus-wide discussion among half the faculty and a significant number of students about the role diversity plays in the classroom.

On the heels of the release of our report, we have been able to build support for several initiatives related to multicultural teaching. One success was that the faculty unanimously passed a resolution that clarified 
and significantly strengthened the college's cultural breadth requirement. It resulted in institutionalizing a teaching for diversity session into the annual new faculty orientation. In addition, support for faculty development in the area of teaching for diversity became formally incorporated into the newly drafted strategic vision for the College of Liberal Arts.

Finally, we used the study as a basis for grant writing to area foundations in order to support curriculum development for teaching for diversity. Hamline University was recently awarded a $\$ 75,000$ challenge grant from the Otto Bremer Foundation for our Race, Gender, and Beyond Project. This will support the development of nine revised or new courses. In the parlance of organizational development, we impacted the system on several levels. We influenced student awareness and student affairs programming and impacted faculty awareness and administrative support for faculty development efforts.

\section{Recommendations for Faculty Developers AdDRessing Race and Gender in the Classroom}

Based on our experiences, we make the following recommendations to faculty developers who would be prophets in their own land:

1) Get your community talking about race and gender. Listen. They have much to share.

2) Although you will hear things that are truly discouraging, they need to be heard and given legitimacy.

3) Assume people are doing the best they know how, and wherever possible, catch them doing things right. Focus on trying to understand, not on judging.

4) Use a multiracial, multiethnic, male-female faculty development research team wherever possible. The more lenses you bring the better you see (Bonilla, 1992).

5) Use "the choir." In preparation for presenting our findings campuswide, we intentionally asked for assistance from faculty experienced and committed to multicultural teaching. This was a critical step in helping to tailor our report to a potentially less supportive and more skeptical audience. While it is often said to be a waste of time to preach to the choir, we found that this process allowed experienced 
faculty to see others benefit from their hard-won lessons. There is no more empowering experience for a teacher, and no better means for affirming the choir.

6) Hitchhike on a current administrative concern. For example, we benefited by being able to capitalize on the current interest in assessment and evaluation by tying excellence in teaching to teaching for diversity.

In the end, what set this effort apart was the extent to which our faculty identified with these findings. These were not perceived as judgments by some external experts from the outside. Rather, the process of searching out Hamline faculty and student voices representing as many perspectives as possible gave the community ownership over the findings as well as investment in pursuing solutions. In using a faculty development process that gave voice to faculty and student concerns, we legitimized those voices. This empowered rather than disempowered us as faculty developers by recognizing members of the community as agents for change. Contrary to conventional wisdom, you can be a prophet in your own land.

\section{REFERENCES}

Adams, A., Bell, L., \& Griffin, P. (Eds.). (1997). Teaching for diversity and social justice: $A$ sourcebook. New York, NY: Routledge.

Bonilla, J. (1992). Walking the walk: Towards creating more racially diverse institutions of higher education. Unpublished doctoral dissertation, University of Massachusetts at Amherst.

Border, L. B., \& Chism, N. V. N. (Eds.). (1992). Teaching for diversity. San Francisco, CA: Jossey-Bass.

Bormann, E.G. (1972). Fantasy and rhetorical vision: The rhetorical criticism of social reality. Quarterly Journal of Speech, 58, 396-407.

Bormann, E. G., Cragan, J. F., \& Shields, D. C. (1994). In defense of symbolic convergence theory: A look at the theory and its criticisms after two decades. Communication Theory, 4, 259-294.

Bormann, E. G., Cragan, J. F., and Shields, D. C. (1996). An expansion of the rhetorical vision component of the symbolic convergence theory: The cold war paradigm case. Communication Monographs 63, 1-28.

Cragan, J. F., \& Shields, D. C. (Eds.). (1981). Applied communication theory and research. Prospect Heights, IL: Waveland.

Kreps, G. (1995). Using focus group discussion to promote organizational re- 
flexivity: Two applied communication field studies. In L. R. Frey (Ed.), Innovations in group facilitation: Applications in natural settings (pp. 177-199). Cresskill, NJ: Hampton Press, Inc.

Krieger, S. (1985). Beyond "subjectivity": The use of the self in social science. Qualitative Sociology, 9 (4), 309-324.

Lincoln, Y., \& Guba, E. (1985). Naturalistic inquiry. Newbury Park, CA: Sage.

Merriam, S. B. (1988). Case study research in education: A qualitative approach. San Francisco, CA: Jossey-Bass.

Mies, M. (1983). Toward a methodology for feminist research. In G. Bowles \& R. Klein (Eds.), Theories of women's studies (pp. 117-139). New York, NY: Routledge.

Morey, A., \& Kitano, M. (Eds.). (1997). Multicultural course transformation in higher education: A broader truth. Boston, MA: Allyn \& Bacon.

Morgan, D., \& Spanish, L. (1984). Focus groups: A new tool for qualitative research. Qualitative Sociology, 7, 253-270.

Orbe, M. P. (1998). Constructing co-cultural theory: An explication of culture, power, and communication. Thousand Oaks, CA: Sage.

Rossman, G., \& Marshal, C. (1989). Designing qualitative research. Newbury Park, CA: Sage.

Schoem, D., Frankel, L., Zuniga, X., \& Lewis, E. (Eds.). (1995). Multicultural teaching in the university. Westport, CT: Praeger.

Tatum, B. D. (1997). Why are all the Black kids sitting together in the cafeteria? And other conversations about race. New York, NY: Basic Books.

\section{Contact:}

James Bonilla

Assistant Professor

Education and Graduate Public Administration \& Management

Hamline University

1536 Hewitt Avenue

St. Paul, MN 55104

Patricia R. Palmerton

Department of Theatre Arts and Communication Studies

Hamline University

1536 Hewitt Avenue

St. Paul, MN 55104 
James Bonnilla has a joint appointment to the College of Liberal Arts and the Graduate School of Public Administration \& Management. His primary duties are teaching courses on Education and Cultural Diversity; Organizational Behavior; and Race, Gender, and the Workplace at the undergraduate and graduate levels. He is also Director, the Bremer Race, Gender, and Beyond Project and serves as an in-house consultant to the faculty on issues of teaching for diversity via grant making and programming. His current research interests include multicultural organizational change in the academy, teaching for diversity and leadership in diverse settings. He lives on a 124 -year-old farm just outside St. Peter, Minnesota.

Patricia Palmerton is Professor of Communication Studies at Hamline University. She has worked extensively nationally with faculty across disciplines on integrating oral communication activities into the classroom. In addition to her work on curriculum development, she teaches courses in rhetorical theory, gender and communication, and interpersonal communication. She has published work on oral communication processes in post-secondary education and the relationship between rhetoric and social change. 